\title{
The Importance of the South Korean Primary Care Group and the Korean Primary Care Assessment Tool: Is It Possible to Sample the Whole Country?
}

\author{
Erno Harzheim ${ }^{1}$, Luiz Felipe Pinto ${ }^{2,3, *}$, Otávio Pereira D'Avila ${ }^{4}$, Lisiane Hauser ${ }^{5}$ \\ ${ }^{1}$ Post-Graduate Studies Program in Epidemiology, Federal University of Rio Grande do Sul, Porto Alegre, Brazil \\ ${ }^{2}$ Federal University of Rio de Janeiro, Rio de Janeiro, Brazil \\ ${ }^{3}$ Post-Doc Studies Program in Primary Care Evaluation, Instituto de Higiene e Medicina Tropical, Universidade Nova de Lisboa, Lisbon, Portugal \\ ${ }^{4}$ Dentistry School, Federal University of Pelotas, Rio Grande do Sul, Pelotas, Brazil \\ ${ }^{5}$ Primary Health Care in Telehealth, Federal University of Rio Grande do Sul, Porto Alegre, Brazil
}

\section{To the Editor}

We were filled with great surprise and joy as we saw the organization of the Seoul professors' team that forms the South Korean Primary Health Care Group from Seoul, one of the few organized groups with major scientific production in East Asia in recent years. Therefore, we decided to submit our "Letter to the Editor" to the leading Journal of Family Medicine in South Korea to make a small contribution to the debate on the use of the Korean Primary Care Assessment Tool (K-PCAT) questionnaire for primary health care assessment from the articles published by Choi et al. ${ }^{1)}$ and Jung et al. ${ }^{2}$ in the October 2010 and April 2011 issues of the Korean Journal of Family Medicine. Choi et al. ${ }^{1)}$ investigated the role of health cooperative clinics. They observed a statistically significant difference for the K-PCAT attributes of coordination function and comprehensiveness among members and non-members of these clinics. However, the sample size was very small (only 100 patients were surveyed). On the other hand, Jung et al., like the late professors Shi et al. ${ }^{3)}$ in 2001, performed data collection from 260 patients with the aid of a computer-assisted telephone interview system. They concluded that primary care physicians outperformed non-primary care physicians, especially in the comprehensiveness domain and the average coordination and family/community orientation attributes.
Therefore, in both studies, the samples were still insufficient to evaluate the affiliation and extension of the quality of primary care and family medicine in the country from K-PCAT.

As described in the literature, K-PCAT, the Korean version of the Primary Care Assessment Tool (PCAT), was validated by the team led by Lee et al. $^{4)}$ in 2009 and one of its limitations that was pointed out was the fact that the sample of users may not have been "sufficient to represent primary care as a whole in the country." Therefore, why not propose to Statistics Korea to include the PCAT question module in its 5-year "time use survey"? $?^{5)}$ In Brazil, the National Institute of Geography and Statistics and the Ministry of Health started the largest national household random sample survey (Pesquisa Nacional de Saúde, PNS-2019) ${ }^{6}$ in the second semester, visiting about 100,000 households. The survey included the adult PCAT short version (25 items) validated in Brazil. We encourage South Korean Primary Health Care Group in Seoul to propose to Statistics Korea and the Ministry of Health and Welfare to do the same. This will allow a baseline to plan future actions and to qualify family medicine and primary care in South Korea.

\section{CONFLICT OF INTEREST}

No potential conflict of interest relevant to this article was reported. 


\section{ORCID}

Erno Harzheim: https://orcid.org/0000-0002-8919-7916

Luiz Felipe Pinto: https://orcid.org/0000-0002-9888-606X

Otávio Pereira D’Avila: https://orcid.org/0000-0003-1852-7858

Lisiane Hauser: https://orcid.org/0000-0003-3324-5533

\section{REFERENCES}

1. Choi YG, Kim K, Choi YJ, Sung NJ, Kim J, Park JH, et al. Patient assessment of primary care of health cooperative clinics in South Korea. Korean J Fam Med 2010;31:765-77.

2. Jung JW, Sung NJ, Park KH, Kim SW, Lee JH. Patients' assessment of community primary and non-primary care physicians in Seoul city of South Korea. Korean J Fam Med 2011;32:226-33.

3. Shi L, Starfield B, Xu J. Validating the adult primary care assessment tool. J Fam Prac 2001;50:161-75.

4. Lee JH, Choi YJ, Sung NJ, Kim SY, Chung SH, Kim J, et al. Development of the Korean primary care assessment tool: measuring user experience: tests of data quality and measurement performance. Int J Qual Health Care 2009;21:103-11.

5. Statistics Korea. Time use survey: overview [Internet]. Daejeon: Statistics Korea [cited 2019 Sep 24]. Available from: http://kostat.go.kr/portal/ eng/surveyOutline/5/4/index.static.

6. Federal University of Rio Grande do Sul. Launch of fieldwork of Brazilian National Health Survey (PNS-2019) from Brazilian Institute of Geography and Statistics (IBGE) [Internet]. Porto Alegre: TelessaúdeRSUFRGS; 2019 [cited 2019 Sep 24]. Available from: https://www.ufrgs. $\mathrm{br} /$ telessauders/noticias/launch-of-fieldwork-of-brazilian-nationalhealth-survey-pns-2019-from-brazilian-institute-of-geography-andstatistics-ibge/. 